\title{
Caractéristiques pondérales des tissus et des contenus digestifs du veau sevré, dans le cas de deux rations concentrées différant par la nature des matières azotées
}

\author{
JP Lallès'1, E Delval², C Poncet² \\ 1 Laboratoire du Jeune Ruminant, INRA, 65, rue de Saint-Brieuc, 35042 Rennes Cedex; \\ 2 Laboratoire de la Dynamique de la Digestion, INRA, Theix, 63122 Ceyrat, France
}

\begin{abstract}
Summary - Feeding dairy calves for 13 wks on concentrate diets differing in nitrogen degradability (pea vs soya bean meal) did not affect the fresh weight of digestive tissues and digesta at a slaughter age of $20 \mathrm{wk}$.
\end{abstract}

Introduction - Le poids des tissus et des contenus digestifs du ruminant dépend de facteurs alimentaires tels que le rapport foin/aliment concentré (Stobo et al, 1966) ou la forme de présentation des aliments (Hodgson, 1973). Ces effets sont expliqués par l'action des fibres et des produits fermentaires (acides gras volatils (AGV), ammoniaque $\left(\mathrm{NH}_{3}\right)$ ) sur le développement respectif de la musculeuse et de la muqueuse du rumen (Candau, 1972), et par des modifications du transit (Hodgson, 1973). L'effet de la dégradabilité ruminale des matières azotées (MA) sur ces paramètres étant peu connu, nous l'avons étudié chez des veaux sevrés à l'aide de rations concentrées de même teneur en fibres mais de dégradabilité des MA différente.

Matériel et Méthodes - De la $77^{\circ}$ à la $20^{\circ}$ semaine d'àge, 12 veaux mâles Frisons reçoivent une ration de foin et d'aliment concentré distribués en proportion conslante $(20: 80)$ à raison de 2 et 8 repas/j respectivement. Les MA des aliments concentrés isoénergétiques et isoazotés proviennent exclusivement du pois (lot $P ; 6$ veaux) ou du tourteau de soja (lot $S ; 6$ veaux); elles ont des dégradabilités ruminales in sacco respectives de 92 et $63 \%$. La teneur en cellulose est voisine dans les 2 rations $(12,1$ et $11,3 \%$ ). Les veaux sont abattus à l'âge de 20 semaines, 7,5 et $1,5 \mathrm{~h}$ après les derniers repas de foin et d'aliment concentré respectivement. Cinq compartiments digestifs (tableau I) sont isolés par double ligature puis séparés. Chaque partie est pesée pleine puis vidée de ses contenus et rincée. Les résultats incomplets de 2 veaux (1/lot) sont éliminés. Les différences entre lots sont analysées par le test $U$ de Mann et Whitney.

Résultats et Discussion - A 20 semaines, les veaux consomment des quantités de matière sèche voisines (lot $P: 2,4$ $\pm 0,2 \mathrm{~kg} / \mathrm{j}$; lot $\mathrm{S}: 2,3 \pm 0,4 \mathrm{~kg} / \mathrm{j})$ et atteignent des poids vifs vides ( $P V V$ ) proches $(86,4 \pm 8,9$ et $84,4 \pm 11,2 \mathrm{~kg})$. Le poids des tissus digestifs et des digesta des 5 compartiments délimités est similaire $(P<$ 0,05 ) dans les 2 lots (tableau I), le tractus digestif plein et son contenu représentant respectivement 22,9 et $15,3 \%$ du PVV. Le poids des contenus des estomacs est 4 fois plus élevé que celui des intestins (12,6 et $3,1 \%$ PVY, contrairement aux tissus correspondants qui ont des poids voisins $(4,2$ et $3,6 \%$ PVY . Le rumen est le 
Tableau I. Poids frais ( $\mathrm{kg} / 100 \mathrm{~kg}$ poids vif vide) des tissus digestifs et des contenus du veau âgé de 20 semaines et sevré avec des rations différant par la nature des matières azotées (moyenne et écart type).

\begin{tabular}{llllll}
\hline & \multicolumn{6}{c}{$\begin{array}{c}\text { Ration } \\
(5 \text { veaux } \\
\text { lot })\end{array}$} & réseau + rumen & feuillet & caillette & intestin grêle & gros intestin \\
\cline { 2 - 6 } & & & & & \\
\hline Tissus digestifs & $2,77(0,37)$ & $0,82(0,17)$ & $0,66(0,11)$ & $2,37(0,48)$ & $1,38(0,20)$ \\
$\begin{array}{c}\text { pois } \\
\text { soja }\end{array}$ & $2,91(0,42)$ & $0,72(0,24)$ & $0,56(0,10)$ & $2,24(0,36)$ & $1,25(0,37)$ \\
Contenus digestifs & $10,44(2,60)$ & $0,35(0,27)$ & $0,69(0,19)$ & $1,80(0,44)$ & $1,38(0,40)$ \\
pois & $12,46(3,32)$ & $0,53(0,24)$ & $0,81(0,32)$ & $1,63(0,25)$ & $1,42(0,17)$ \\
soja & & & & & \\
\hline
\end{tabular}

plus lourd des compartiments gastriques dont il représente 67 et $90 \%$ du poids des tissus et des contenus respectivement. Le feuillet et la caillette ont des contributions faibles (tissus : 19 et $14 \%$ respectivement; contenus : 4 et $6 \%$ ). Ces résultats sont en accord avec ceux de Stobo et al (1966).

Dans notre essai, le poids des tissus et des contenus n'est pas affecté par la nature des MA alimentaires, comme l'ont observé Nocek et al (1984) au niveau des estomacs du veau sevré. Cette absence d'effet de la ration sur le poids des contenus était attendue car les aliments, ingérés et digérés en quantités voisines, séjournent pendant des durées similaires dans les différents compartiments digestifs des veaux des 2 lots (Lallès, 1988).

Les fibres alimentaires stimulent le développement de la musculeuse ruminale alors que les $\mathrm{AGV}$ et $\mathrm{NH}_{3}$ agissent sur celui de la muqueuse (Candau, 1972). Des rations également pourvues en fibres, comme dans notre essai, sont alors susceptibles de conduire à une musculature ruminale de même poids. Un effet trophique particulier de $\mathrm{NH}_{3}$ sur la muqueuse devrait par contre affecter son poids et vraisemblablement le poids total des tissus ruminaux car elle en représente $70 \%$ avec des rations concentrées (Nocek et al, 1984). Bien que la concentration ruminale de $\mathrm{NH}_{3}$ soit 2,5 fois plus élevée avec la ration pois qu'avec la ration soja (Lallès, 1988), nous n'observons pas de différence de poids des tissus entre rations. Ceci suggère que l'effet trophique de $\mathrm{NH}_{3}$, s'il existe, est masqué par celui des AGV, en concentrations voisines entre lots dans notre essai (Lallès, 1988).

En conclusion, le poids des tissus et des contenus digestifs du veau sevré n'est pas influencé par la dégradabilité des MA alimentaires.

Candau M (1972) Thèse de Docteur ès Sciences Naturelles. Paris VI

Hodgson J (1973) Anim Prod 17, 129-138

Lallès JP (1988) Thèse de Docteur-Ingénieur, ENSA, Rennes

Nocek JE, Heald WC, Polan CE (1984) J Dairy Sci 67, 334-343

Stobo IJF, Roy JHB, Gaston HJ (1966) Br J Nutr $20,171-188$ 